\title{
A GEOLOGIA NO PLANO DE MANEJO DO PARQUE ESTADUAL DE VILA VELHA, PR*
}

\author{
MÁRIO SÉRGIO DE MELO, LUIZ CARLOS GODOY,PAULA MARIELE MENEGUZZO \& \\ DIEGO JURASKI PEREIRA DA SILVA
}

\begin{abstract}
GEOLOGY IN THE MANAGEMENT PLAN OF THE VILA VELHA STATE PARK, SOUTHERN BRAZIL As a requirement of the management plan of the Vila Velha State Park (PEVV), Paraná State, Southern Brazil, studies included geological and geomorphological mapping, and photointepretation of geological and relief features in several scales (1:70.000 to 1:2.000, with final maps 1:40.000). The field works and data analysis emphasised main aspects related to the conservation unit. The PEVV is situated in the eastern edge of the Paraná Basin, in a region strongly affected by faults, fractures and dikes related to Mesozoic activity in the Ponta Grossa Arch. The geological units present are the Furnas and Ponta Grossa formations (Devonian), the Itararé Group (Carboniferous-Permian), Serra Geral diabase dikes (Lower Cretaceous) and Quaternary alluvial and coluvial sediments. Singular landforms in the PEVV are escarpments, inselbergs, ruiniform landscapes, towers, pinnacles, grikes, corridors, labyrinths, 'furnas' (sinkholes), humid depressions, ponds, waterfalls, rapids, 'tafoni', solution pans, 'lapiés', alveolus, anastomosed tunnels, corrosion cones, polygonal fractures and termite perforations. The main results of the geological studies concern the indication of specific interest areas or themes for visitation, protection of special areas, recovery of degraded areas, utilization of adequate construction material, indication of hazardous situations, indication of specific equipments, indication of areas for new attractivenesses development, indication of themes for new scientific research, indication of priority areas for the enlargement of the protected perimeter, indication of activities for environmental interpretation, information for the production of printed material and human resources training.
\end{abstract}

Keywords: Vila Velha State Park, management plan, Furnas Formation, Vila Velha Sandstone.

Resumo Estudos geológicos realizados no Parque Estadual de Vila Velha (PEVV) para subsídio ao plano de manejo incluíram fotointepretação em diversas escalas, trabalhos de campo e produção de mapas geológicos e geomorfológicos em escala 1:40.000, enfatizando-se aspectos de interesse para a unidade de conservação. O PEVV situa-se na borda oriental da Bacia do Paraná, em área fortemente afetada por falhas, fraturas e diques relacionados à atividade mesozóica no Arco de Ponta Grossa. As unidades geológicas que aparecem no parque são: formações Furnas e Ponta Grossa (Devoniano); Grupo Itararé (Carbonífero-Permiano); diques de diabásio Serra Geral (Eocretáceo); sedimentos aluviais e coluviais quaternários. Feições de relevo singulares do PEVV, que constituem sua principal razão de ser, são: escarpamentos, morros testemunhos, relevos ruiniformes; torres e pináculos; fendas, corredores e labirintos; furnas; depressões úmidas, secas e lagoas; cachoeiras e corredeiras; lapas; entalhes de base de paredes rochosas; caneluras ou canaletas; bacias de dissolução; alvéolos; túneis anastomosados e cones de erosão; juntas poligonais; perfurações produzidas por cupins. Os principais subsídios da Geologia para o plano de manejo do PEVV foram: indicação de áreas ou temas de interesse específico para visitação; proteção de áreas especiais; recuperação de áreas degradadas e prevenção de novos impactos; utilização de materiais de construção adequados; indicação de possíveis situações de risco; indicação de equipamentos específicos; indicação de áreas para desenvolvimento de novos atrativos; indicação de temas para novas pesquisas científicas; indicação de eventuais áreas de ampliação da unidade de conservação; indicação de atividades de interpretação ambiental; produção de material de informação, divulgação e treinamento; treinamento de recursos humanos.

Palavras-chave: Parque Estadual de Vila Velha, plano de manejo, Formação Furnas, Arenito Vila Velha.

INTRODUÇÃO Vila Velha é a denominação de um notável agrupamento de relevo ruiniforme esculpido em arenitos, de grande apelo cênico e valor científico para a Geologia e Geomorfologia, bem como para estudos ambientais, visto que o relevo de exceção abriga ecossistemas típicos dos Campos Gerais do Paraná, incluindo espécies da flora e fauna endêmicas da região.

As esculturas naturais em arenito têm recebido denominações diversas sugeridas pelo imaginário dos visitantes leigos: cidade ciclópica, camelo, esfinge, proa do navio, garrafa, tartaruga e a taça, esta o símbolo de Vila Velha, além de dezenas de outras, cujas alturas variam de poucos metros a cerca de $20 \mathrm{~m}$, distribuídas numa área com cerca de 10 ha. O conjunto principal com relevo ruiniforme é um notável afloramento de arenitos periglaciais, de gênese discutida, onde as esculturas refletem a interação de vários fatores: características litológicas da rocha sedimentar, estrutu- ras tectônicas e atectônicas, processos intempéricos e erosivos atuantes, dentre outros. Citada como exemplo de ação de processos eólicos, este é um dos mais consagrados equívocos da literatura geológica e geomorfológica brasileira.

Situada cerca de $80 \mathrm{~km}$ a WNW de Curitiba e a $20 \mathrm{~km}$ aESE de Ponta Grossa (Fig. 1), Vila Velha há muito tempo notabilizou-se como importante pólo de visitação turística, contabilizando-se média de 200.000 visitantes/ano ao longo da década de 1990. A singularidade das esculturas em arenito levou à criação do Parque Estadual de Vila Velha (PEVV), com 3.122,11 ha, pela Lei Estadual $\mathrm{n}^{\circ} 1.292$, de 12 de outubro de 1953 . Além do relevo ruiniforme em arenitos, o parque criado incluiu ainda outras feições notáveis, como as furnas e a Lagoa Dourada.

O PEVV foi o primeiro parque estadual do Paraná. Se por um lado essa antiguidade contribuiu para a preservação de alguns de 
seus aspectos naturais, por outro dificultou a adaptação à legislação ambiental, relativamente recente. Até o ano 2000 o PEVV ainda era administrado por três instituições com objetivos muito distintos (turismo, pesquisa agropecuária e proteção ambiental), e não existia plano de manejo que disciplinasse sua utilização.

A partir de 2000, iniciou-se um esforço de revitalização do PEVV, visando adequá-lo à legislação atual, e dotá-lo de plano de manejo e infra-estrutura compatível com a grande visitação observada. Foi neste contexto de revitalização que foram realizados os estudos geológicos aqui apresentados.

ODecreto $^{\circ} 4.340$ de $22 / 08 / 2002$, que regulamenta lei anterior que dispõe sobre o SNUC - Sistema Nacional de Unidades de Conservação, indica características gerais do plano de manejo: estabelecimento dos limites da UC; compatibilização, integração e otimização das atividades desenvolvidas; regulamentação da concessão de uso pelas populações tradicionais; uniformização de conceitos e metodologias; fixação de diretrizes para o diagnóstico da UC; zoneamento; programas de manejo; estabelecimento de fases de implementação e de prazos de avaliação e revisão; caráter participativo no manejo; desenvolvimento de pesquisas necessárias para o manejo da UC e área de amortecimento. Tendo em vista estas diretrizes gerais, devem ser orientados os levantamentos, inclusive os de natureza geológica e geomorfológica.

Os estudos geológicos realizados no PEVV não diferiram significativamente dos procedimentos usuais em mapeamentos geológicos: foram utilizadas fotografias aéreas em escalas 1:70.000,
1:25.000 e 1:2.000, que apoiaram levantamentos de campo realizados entre abril e junho de 2002. Para dar suporte ao planejamento do uso da unidade de conservação (IBAMA 2002), além do mapeamento de unidades geológicas foi realizado também mapeamento de feições geomorfológicas de destaque e de unidades de relevo, com mapas finais em escala 1:40.000(UEPG 2002). Os mapeamentos e levantamentos foram orientados para atender às diretrizes gerais dos planos de manejo.

GEOLOGIA REGIONAL O PEVV localiza-se próximo à borda oriental da Bacia do Paraná, cerca de $10 \mathrm{~km}$ a oeste do contato erosivo das unidades sedimentares paleozóicas sobre o embasamento proterozóico, que aparece a nordeste da área estudada. Este embasamento é representado por rochas metamórficas de grau baixo a médio do Supergrupo Açungui (Grupo Itaiacoca e Formação Água Clara, Meso a Neoproterozóico, Campanha \& Sadowski 1998) e vastos complexos granitóides calco-alcalinos associados (Cunhaporanga, a noroeste da Faixa Itaiacoca, e Três Córregos, a sudeste desta faixa). As unidades da Bacia do Paraná presentes na área estudada são as formações Furnas e Ponta Grossa (Devoniano), e a base do Grupo Itararé (Carbonífero Superior). Estas unidades estão incluídas nas duas megasseqüências basais da Bacia do Paraná (Assine 1996, Milani et al. 1998).

Formação Furnas A Formação Furnas assenta discordantemente sobre rochas do embasamento cristalino ou da Formação Iapó,

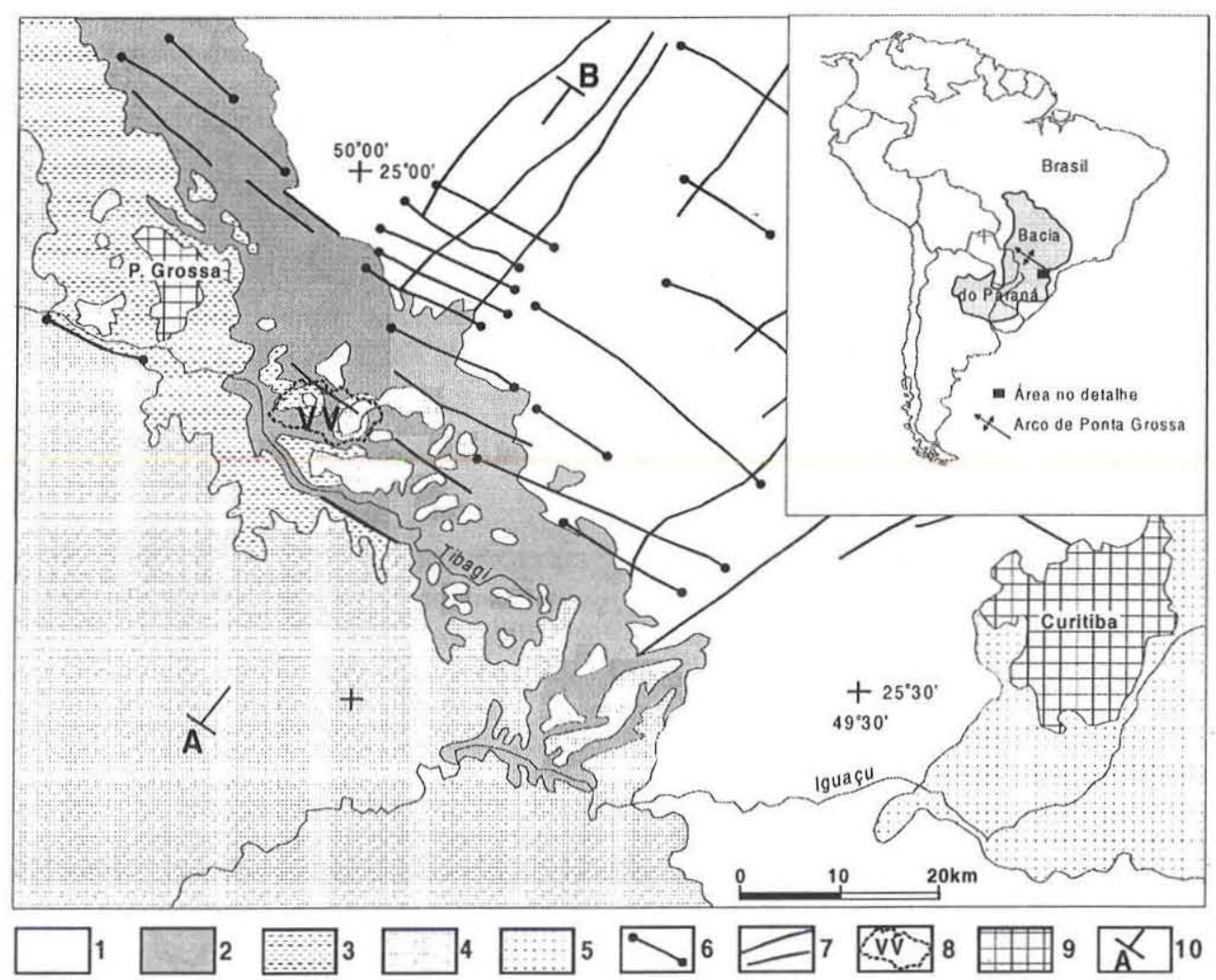

Figura 1 - Mapa geológico regional e localização do Parque Estadual de Vila Velha. 1: embasamento proterozóico; 2: Formação Furnas (D); 3: Formação Ponta Grossa (D); 4: Grupo Itararé (C-P); 5: sedimentos da Bacia de Curitiba (T); 6: diques de diabásio do Magmatismo Serra Geral (K); 7: principais falhamentos; 8: localização do PEVV; 9: áreas urbanas; 10: posição da seção da Fig. 2 (modificado de MINEROPAR, 1989). 
enquanto a passagem para as unidades sobrepostas é gradacional, quando passa para a Formação Ponta Grossa, ou discordante, quando rochas do Grupo Itararé sucedem o Arenito Furnas.

É constituída dominantemente de arenitos médios a grossos de coloração clara, feldspáticos e/ou caulínicos, com grãos angulosos a subangulosos, regularmente selecionados. Os arenitos estão dispostos em sets com espessuras de 0,5 a 5,0 m com geometria tabular, lenticular e cuneiforme, com marcante estratificação cruzada planar, tangencial na base ou acanalada (Assine 1996). Na parte inferior da formação predominam arenitos grossos, imaturos, com ocorrências descontínuas de arenitos conglomeráticos e conglomerados quartzosos. Em direção ao topo, predominam arenitos mais finos, com níveis de siltitos argilosos micáceos. Alguns autores (Assine 1996, Borgui 1996) têm sugerido a possibilidade de subdivisão da Formação Furnas com base nestas variações de fácies sedimentares.

A idade da Formação Furnas é considerada como estendendo-se do Neo-Siluriano (Pridoliano) ao Eo-Devoniano (Lockoviano/ Praguiano), segundo Assine (1996) e Bergamaschi (1999). A interpretação do ambiente deposicional tem suscitado muitas discussões. Bigarella et al. (1966) e Lange \& Petri (1967) consideraram origem marinha para a formação. Northfleet et al. (1969) e Schneider et al. (1974) admitiram origem fluvial. Assine et al. (1994) propuseram que a Formação Furnas foi depositada em sistemas de deltas construídos por rios entrelaçados. Borgui (1996) e Assine (1996) consideraram a formação como resultado do retrabalhamento marinho de paleocorrentes flúvio-costeiras.

Formação Ponta Grossa A Formação Ponta Grossa assenta-se sobre a Formação Furnas, em contato gradacional, e é sobreposta por rochas do Grupo Itararé, através de contatos discordantes.

Lange \& Petri (1967) subdividiram a Formação Ponta Grossa, da base para o topo, em três membros: Jaguariaíva, Tibagi e São Domingos. O Membro Jaguariaíva (cerca de $100 \mathrm{~m}$ de espessura)é constituído de folhelhos laminados fossilíferos e bioturbados, com lentes de arenitos finos subordinadas, depositados num contexto de plataforma marinha rasa, de idade correspondente ao intervalo Praguiano a Frasniano (Assine 1996; Bergamaschi 1999). O Membro Tibagi (20 a $35 \mathrm{~m}$ de espessura) é constituído de arenitos finos a muito finos lenticulares, fossilíferos, entremeados em folhelhos sílticos, depositados em sistemas marinhos plataformais sob ação de ondas (Assine et al. 1998), de idade eifeliana (Daemon et al. 1967 e Lange \& Petri 1967). O Membro São Domingos (90 m de espessura na área-tipo) é constituído de folhelhos laminados de cor cinza com arenitos finos subordinados, depositados em ambiente marinho no Eifeliano-Frasniano (Lange e Petri 1967; Daemon et al. 1967).

A Formação Ponta Grossa é conhecida pelo seu rico conteúdo fossilífero, que inclui bivalves, gastrópodes, trilobitas, braquiópodes, cricoconarídeos, dentre outros, diversificados sobretudo nos dois membros inferiores, constituindo a denominada fauna da "província malvinocáfrica" (Boucot \& Gill 1956). O Membro São Domingos é menos fossilífero e com menor número de espécies que os inferiores, faltando-lhe formas tipicamente malvinocáfricas, o que é interpretado como consequiência do aquecimento das águas pelo deslocamento para norte do Gondwana Ocidental durante o Devoniano Médio (Isaacson 1996).

Grupo Itararé O Grupo Itararé, unidade basal do Supergrupo Tubarão, de idade permo-carbonífera, corresponde a uma complexa associação de litotipos (e.g. tilitos, diamictitos, varvitos, arenitos e folhelhos), depositada sob condições flúvio-glaciais, gláciomarinhas e marinhas, em conseqüência do degelo das geleiras desenvolvidas sobre extensa área da margem meridional do Gondwana (Milani et al. 1994).

A divisão estratigráfica do Grupo Itararé tem sido muito discutida. Com base em dados de afloramentos, Schneider et al. (1974) propuseram subdivisão em três formações (Campo do Tenente, Mafra e Rio do Sul), aplicável aos estados de Santa Catarina e Paraná. França \& Potter (1988), com base em dados de testemunhos de sondagens, propuseram nova subdivisão, nas formações Lagoa Azul, Campo Mourão e Taciba. Estes autores mantiveram a denominação de Formação Aquidauana para os sedimentos terrígenos avermelhados da porção norte-noroeste da bacia.

A Formação Lagoa Azul, composta por arenitos, folhelhos e diamictitos, constitui a unidade basal e não-aflorante do Grupo Itararé da região centro-sul do Estado de São Paulo, norte do Estado de Paraná e sudeste do Estado de Mato Grosso do Sul (França \& Potter 1988). Repousando sobre a Formação Lagoa Azul ou unidades mais antigas, ocorre a Formação Campo Mourão, constituída dominantemente por arenitos com folhelhos, siltitos, diamictitos e lamitos seixosos subordinados. De acordo com Milani et al. (1994), a Formação Campo Mourão equivaleria às formações Campo do Tenente e Mafra de Schneider et al. (1974). As rochas do Grupo Itararé no PEVV, dentre as quais o Arenito Vila Velha (Maack 1946), pertenceriam à formação Campo Mourão.

Intrusivas básicas a intermediárias (Formação Serra Geral) Nas rochas paleozóicas da Bacia do Paraná ocorrem rochas intrusivas básicas a intermediárias mesozóicas relacionadas ao Magmatismo Serra Geral (Grupo São Bento), representadas principalmente por diques e soleiras de diabásio, de idade eocretácea. Apresentam coloração cinza escura a preta e granulação milimétrica a submilimétrica. A espessura dos corpos ígneos varia de submétrica a dezenas de metros. Sua origem está ligada ao Arco de Ponta Grossa, o qual provocou fraturas profundas, por onde ascendeu o magma básico, testemunhando intensa atividade vulcânica durante a fragmentação do Gondwana. A direção preferencial dos diques de diabásio é $\mathrm{N} 40^{\circ}-60^{\circ} \mathrm{W}$, longitudinal ao eixo do arqueamento.

O Arco de Ponta Grossa A região do PEVV situa-se no flanco sudoeste do Arco de Ponta Grossa (Figs. 1 e 2), importante estrutura de direção NW-SE da Bacia do Paraná. Éum alto estrutural com eixo inclinado para NW, ativo desde o Paleozóico, mas palco de intensa atividade tectônica sobretudo no Mesozóico. Nesta época, os movimentos verticais ao longo do arqueamento atingiram seu apogeu, e profundas fraturas longitudinais deram passagem ao magma basáltico. O arqueamento foi considerado por Herz (1977) como um ramo abortado de junção tríplice durante a fragmentação do Gondwana e abertura do Atlântico Sul.

O Arco de Ponta Grossa é responsável por algumas das feições geológicas e geomorfológicas notáveis do flanco leste da Bacia do Paraná:

a) fraturas, falhas e enxames de diques de direção NW-SE, os quais controlam o relevo e a hidrografia;

b) concavidade (em mapa) do contato dos sedimentos paleozóicos sobre o embasamento, e exposição de unidades inferiores não aflorantes em muitos locais da bacia;

c) escalonamento do relevo em planaltos de origem erosiva.

Outras estruturas geológicas Reconhecem-se três direções principais de estruturas rúpteis tectônicas na Bacia do Paraná 


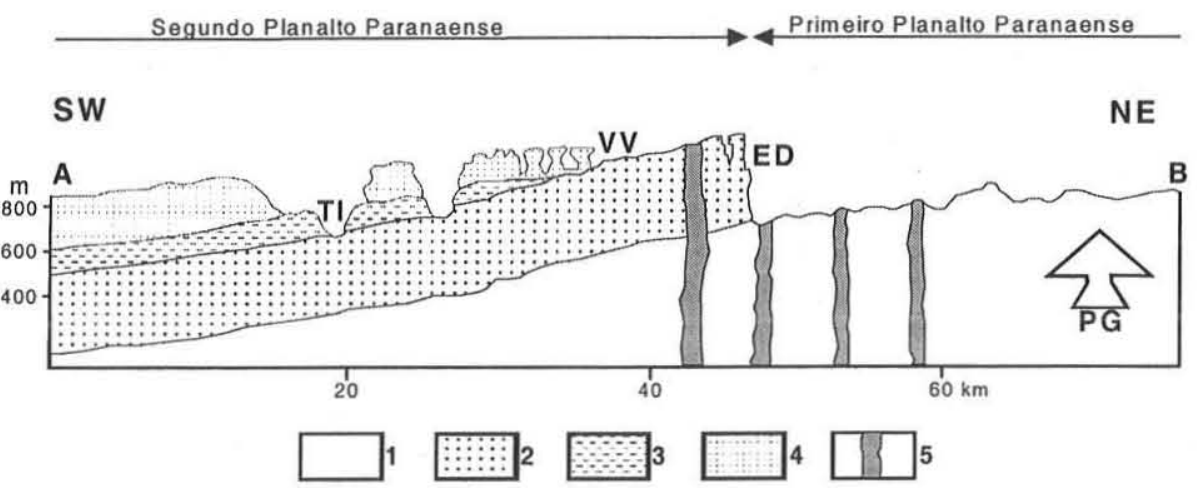

Figura 2 - Seção esquemática que mostra a relação do Parque Estadual de Vila Velha com a estrutura geológica regional (ver localização na Fig. 1). 1: embasamento proterozóico; 2: Formação Furnas (D); 3: Formação Ponta Grossa (D); 4: Grupo Itararé(CP); 5: diques de diabásio do Magmatismo Serra Geral (K); PG: Arco de Ponta Grossa; ED: Escarpa Devoniana; VV: PEVV; TI: Rio Tibagi.

\section{(Zalán et al. 1991):}

a) NE-SW, correspondente às direções do embasamento proterozóico da bacia, reativadas recorrentemente, com movimentos horizontais e verticais;

b) NW-SE, preexistentes e reativadas principalmente no Neojurássico e Eocretáceo, com movimentos verticais dominantes; associam-se à ruptura do Gondwana e magmatismo da Formação Serra Geral;

c) E-W, supostamente originadas a partir do Triássico, ligadas à abertura do Atlântico Sul, em vista do paralelismo com as zonas de fraturas oceânicas.

Todas estas direções estruturais principais foram reativadas durante os movimentos ao longo do Arco de Ponta Grossa no Mesozóico, e ocorrem na região do PEVV, impondo marcante controle estrutural da drenagem, sobretudo do Rio Quebra Perna. Falhas e fraturas do sistema NW-SE muitas vezes encontram-se penetradas por intrusões básicas relacionadas ao Magmatismo Serra Geral. Outros dois conjuntos de fraturas ocorrem nos principais platôs de arenitos de Vila Velha (Melo \& Coimbra 1996):

a) subverticais com distribuição concêntrica, paralelamente às bordas dos platôs areníticos;

b) suborizontais parcialmente controladas pela estratificação e originadas por alívio de carga.

GEOMORFOLOGIA REGIONAL OPEVV situa-se emporção colinosa, com morros testemunhos sustentados por arenitos, incluída no Segundo Planalto Paranaense. Este planalto constitui um dos compartimentos do relevo escalonado do Estado do Paraná (Fig. 3), com topos nivelados entre 1100 e 800 m, com suave caimento para oeste.

Rochas sedimentares paleozóicas da Bacia do Paraná, com intrusivas básicas associadas, sustentam o Segundo Planalto Paranaense. Este é delimitado por dois marcantes degraus topográficos, cada um deles com até cerca de $300 \mathrm{~m}$ de desnível, representados pela Escarpa Devoniana a leste (localmente denominada Serra de São Luís do Purunã) e Serra Geral a oeste.

Uma feição típica do reverso da Escarpa Devoniana na borda do Segundo Planalto Paranaense é representada pelas "furnas", depressões erosivas que dão nome à Formação Furnas. Trata-se de feições de desabamento, atribuídas principalmente a fenômenos de erosão subterrânea do arenito, favorecida ao longo de estruturas rúpteis e sedimentares (Maack 1946 e 1956, Soares 1989, Melo 1999). Existem dezenas de furnas conhecidas na região de afloramento do Arenito Furnas no Segundo Planalto Paranaense, as maiores com até três centenas de metros de diâmetro e profundidade conhecida de até $110 \mathrm{~m}$.

GEOLOGIA DO PEVV As unidades que aparecem no PEVV são apresentadas na figura 4. As mais antigas encontram-se truncadas por estruturas rúpteis, que têm forte influência no desenvolvimento das feições e compartimentação do relevo.

Formação Furnas Ocorre na porção oeste do PEVV, e também nos terrenos mais baixos ao longo do vale do Rio Quebra-Perna e da porção de montante do arroio que faz o limite leste do PEVV, afluente do Rio Guabiroba.

As melhores exposições da Formação Furnas estão nas furnas $\mathrm{n}^{\circ} 1$ e 2 (Fig. 5), e também ao longo de faixa de afloramentos na margem esquerda do Rio Quebra-Perna. Nestes últimos locais, formam-se as características lapas, com tetos rochosos e paredes controlados pelas estruturas sedimentares típicas dos arenitos, e também estruturas rúpteis associadas. Estas lapas constituem abrigos naturais, e nas proximidades do PEVV nelas foram encontrados muitos sítios arqueológicos (v.g. Chmyz 1976, Rocha et al. s.d., Santana \& Melo 2001).

Na área de exposição, a Formação Furnas exibe as características que lhe são típicas: predominam arenitos finos a médios, com níveis conglomeráticos restritos, caulínicos, o que lhes confere coloração clara, e com marcantes estruturas sedimentares, principalmente estratificações plano-paralelas e cruzadas tabulares. Aparecem também marcas onduladas indicativas das paleocorrentes que depositaram os arenitos.

Os arenitos da Formação Furnas, assim como aqueles do Grupo Itararé, exibem formas singulares resultantes da associação de processos de dissolução e erosão mecânica, os chamados relevos ruiniformes (Melo \& Coimbra 1996). Particularmente, a Formação Furnas condiciona o aparecimento das grandes depressões, que incluem as furnas, lagoas, depressões secas ou úmidas, resultantes de processos erosivos subterrâneos que ocorrem em grande profundidade.

Formação Ponta Grossa Rochas típicas da Formação Ponta Grossa ocorrem somente em locais do extremo leste dentro dos limites do PEVV. Nos mapas preexistentes, erroneamente considerou-se diamictitos do Grupo Itararé como pertencentes à Formação Ponta Grossa (Fig. 1). Esta compreende folhelhos silto-argilo- 


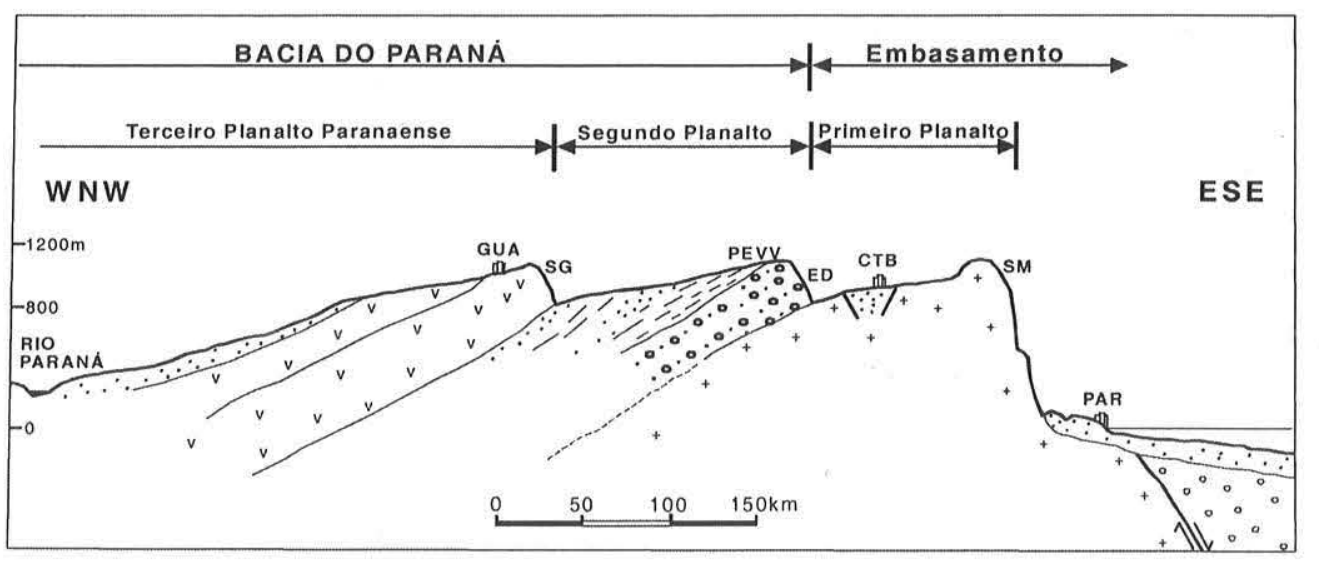

Figura 3 - Seção esquemática WNW-ESE da estrutura do relevo do Estado do Paraná. PAR: Paranaguá; SM: Serra do Mar; CTB: Curitiba; ED: Escarpa Devoniana; PEVV: Parque Estadual de Vila Velha; SG: Serra Geral; GUA: Guarapuava.

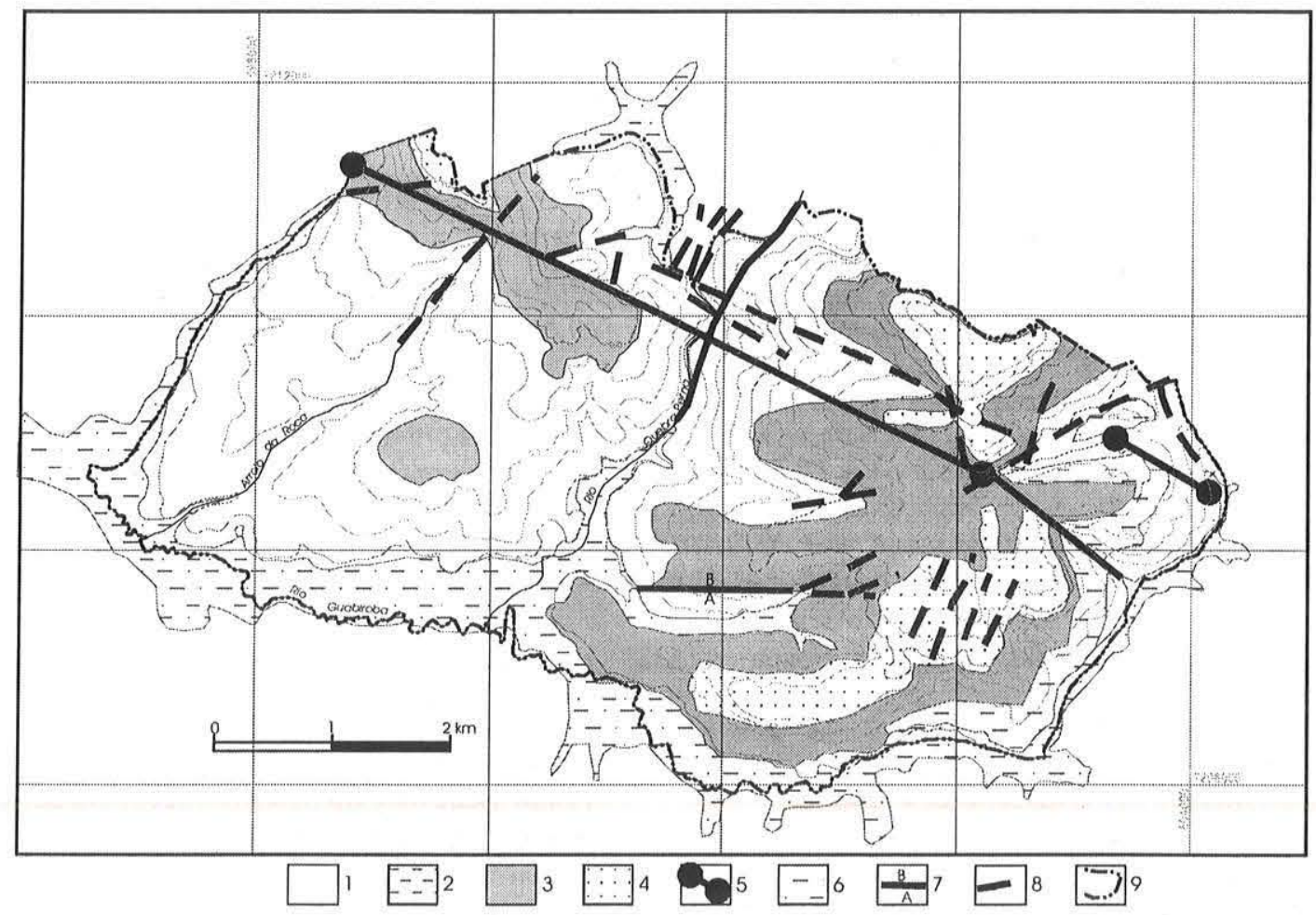

Figura 4 - Mapa geológico do Parque Estadual de Vila Velha. 1: Formação Furnas (Devoniano); 2: Formação Ponta Grossa (Devoniano); 3: rochas indiferenciadas do Grupo Itararé (Carbonífero-Permiano); 4: arenitos do Grupo Itararé (CarboníferoPermiano); 5: diques de diabásio do Magmatismo Serra Geral (Cretáceo); 6: sedimentos aluviais e coluviais quaternários; 7: falha normal; 8: principais lineamentos; 9: limites do PEVV.

sos micáceos, cinzentos, apresentando fósseis (moldes) de braquiópodes. Embora o afloramento de folhelho seja relativamente pequeno, constitui a única exposição com fósseis típicos da Formação Ponta Grossa dentro do PEVV.

Estratigraficamente a Formação Ponta Grossa posiciona-se entre a Formação Furnas sotoposta, mais antiga, e o Grupo Itararé, sobreposto. Erosão ocorrida entre o final da deposição da Formação Ponta Grossa e o início da deposição do Grupo Itararé foi responsável pelo desaparecimento da Formação Ponta Grossa em toda a porção oeste do PEVV.
Grupo Itararé As rochas sedimentares da parte leste do PEVV bem como as que sustentam os platôs, morros testemunhos que se destacam na topografia tanto no parque como em áreas vizinhas (Fortaleza, Toquinhas, Arcos) pertencem ao Grupo Itararé. Estas são de natureza variada, refletindo os muitos sub-ambientes do ambiente glacial em que foram formadas. Ocorrem na área do PEVV diamictitos, ritmitos, argilitos, folhelhos e arenitos. Nos trabalhos realizados, foi possível separar as rochas sedimentares do Grupo Itararé em duas unidades, representadas na figura 4:

- unidade basal contendo diamictitos, argilitos, folhelhos e 


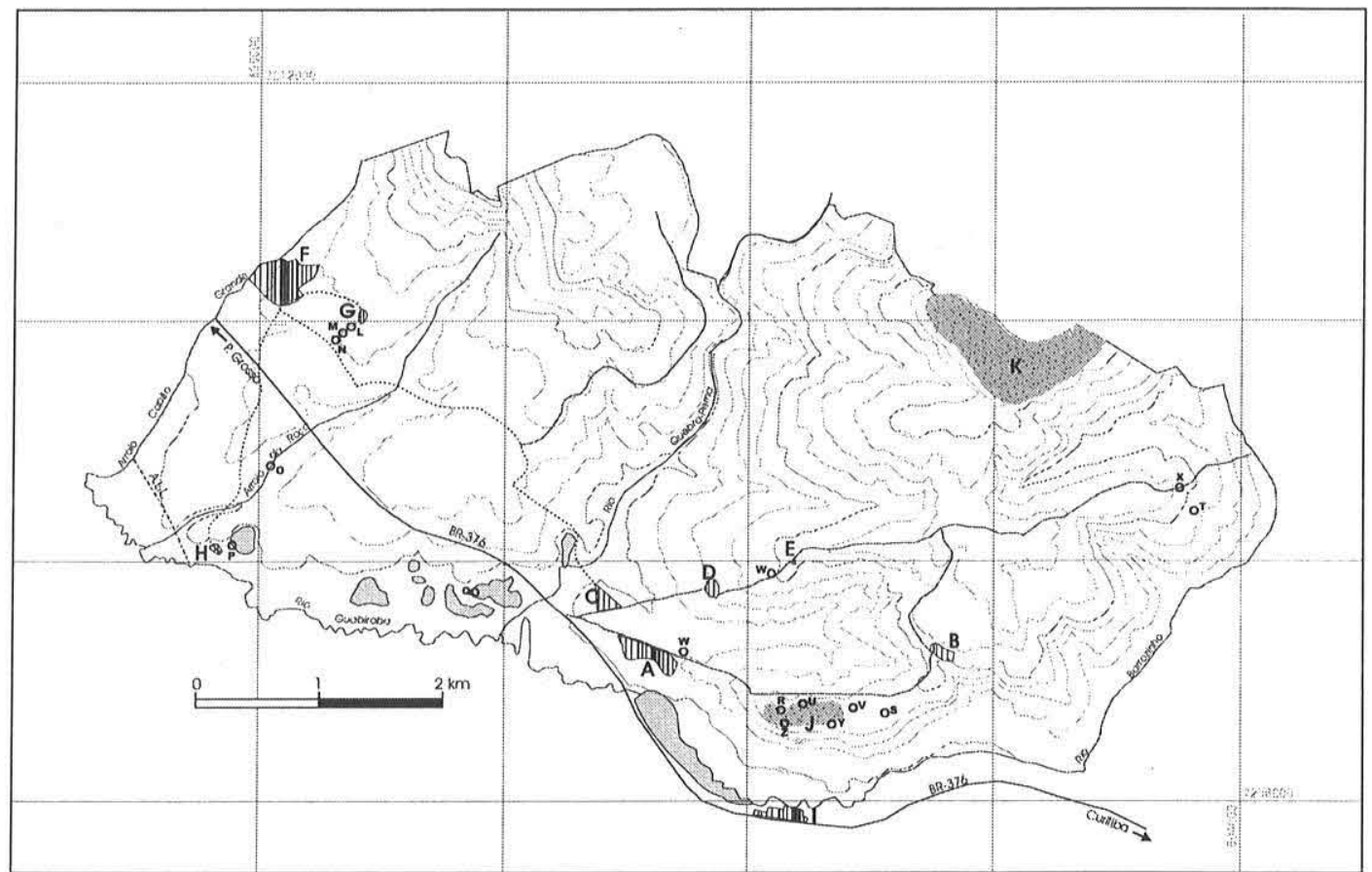

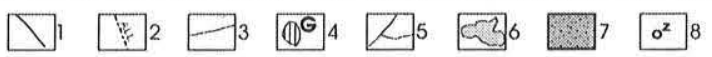

Figura 5 - Principais acessos, instalações e feições de interesse geológico no PEVV. 1) Rodovia (BR-376); 2) Ferrovia (América Latina Logística); 3) Acessos internos do parque; 4) Instalações - A) Administração, recepção, estacionamento; B) Antigos museu e piscina; C) Antigo camping; D) Capela; E) Alojamento de pesquisa (antiga casa do guarda-parque); F) Polícia Florestal e antigo IAPAR; G) Recepção e estacionamento das furnas; H) Estacionamento e recepção da Lagoa Dourada; I: Posto de abastecimento; 5) Rede de drenagem; 6) Lagos e lagoas; 7) Platôs areníticos - J: Vila Velha; K: Fortaleza; 8) Principais feições de interesse geológico - L) Furna $n^{\circ}$ 1; M) Furna $n^{\circ}$ 2;N) Furna $n^{\circ}$ 3; O) Furna $n^{\circ} 4$; P) Lagoa Dourada; Q) Lagoa Tarumã; R) relevos ruiniformes; S) "taça"; T) ocorrência de fósseis devonianos; U) pseudo-estratificações no Arenito Vila Velha; V) fraturas no Arenito Vila Velha com franjas botrioidais de óxidos de ferro e manganês; W) áreas-de-empréstimo de solo; X) erosão ao longo de aceiro; $Y$ ) trilha sul do platô de Vila Velha revestida com cascalho de folhelhos devonianos; Z) Gruta da Pedra Suspensa.

arenitos subordinados, indicados na figura 4 como rochas indiferenciadas do Grupo Itararé;

- unidade de topo contendo dominantemente os arenitos avermelhados que sustentam os platôs do relevo local; corresponde ao Arenito Vila Velha de Maack (1946).

A sucessão dos diversos tipos de rochas do Grupo Itararé, que apresentam diferentes resistências à erosão, em litossomas aproximadamente horizontais, determina o aparecimento de muitas cornijas no relevo local.

Uma característica dos diamictitos do Grupo Itararé é o fato de apresentarem regolito contendo muitas concreções limoníticas, resultantes de sua decomposição intempérica. Estas concreções são comumente exploradas como fonte de cascalho para o leito de estradas ou outros tipos de aterro. Caixas-de-empréstimo deste tipo foram observadas em cinco locais. Embora já não exploradas, a exposição de horizontes inferiores do solo, pela remoção do material superficial, causa processos erosivos significativos (sulcos, ravinas), que determinam a necessidade de procedimentos para recuperação dessas áreas.

Os arenitos rosados do topo do Grupo Itararé na área constituem o denominado Arenito Vila Velha (Maack 1946), que sustenta os morros testemunhos que dominam a paisagem local. Este arenito apresenta estratificação incipiente, frequiente aspecto maciço e presença de intraclastos argilosos, atributos que sugerem ressedimentação por fluxos gravitacionais subaquosos. Estratificações cruzadas de baixo ângulo e marcas onduladas indicam ação de correntes aquosas (França et al. 1996), talvez num ambiente marinho raso sob influência de marés (Canuto et al. 1997). $\mathrm{O}$ tom rosado dos arenitos é devido a cimento ferruginoso, o qual determina também a existência de horizontes com diferentes resistências à erosão, o que contribui para a bizarria das formas de erosão observadas.

Característica marcante do Arenito Vila Velha é a presença do relevo ruiniforme (Melo \& Coimbra 1996), marcado por rica associação de formas incluindo caneluras, bacias, alvéolos, túneis anastomosados, cones de dissolução, topos pontiagudos, flancos convexos, etc., que originam esculturas naturais singulares, das quais a "taça" é um exemplo. Tais feições derivam sobretudo da ação das águas pluviais, do calor do sol e da atividade orgânica sobre rochas, estas portadoras de descontinuidades, tais como fraturas, estruturas sedimentares, textura e cimentação diferenciadas, que colaboram nas ornamentações.

Outra característica marcante do Arenito Vila Velha é representada por pseudo-estratificações, resultantes de diferenciações na cimentação por óxidos de ferro e manganês de soluções percolantes a partir de estruturas rúpteis (Melo et al. 1999).

Diques de Diabásio do Magmatismo Serra Geral Foram identi- 
ficados dois diques de diabásio de direção N80W na área do PEVV. Somente no leito do Rio Quebra-Perna foi possível observar a rocha pouco alterada. Apresenta textura fina, e coloração escura homogênea. Os diques são pouco espessos, estimando-se possança de cerca de $5 \mathrm{~m}$ para o dique maior, que estende-se por cerca de $6 \mathrm{~km}$ ao longo do parque (Fig. 4).

Sedimentos Aluviais e Coluviais Quaternários ORio Guabiroba, o Quebra-Perna e seus principais afluentes apresentam planícies aluviais relativamente extensas. Essas planícies muitas vezes gradam lateralmente para rampas suavemente inclinadas, indicando que tratam-se de complexas associações de depósitos aluviais típicos com depósitos coluviais, estes desenvolvidos ao longo da parte inferior das encostas.

No Rio Guabiroba, que marca o limite sul do PEVV, a planície mostra níveis diferenciados de terraços aluviais, que indicam acumulação em vários eventos deposicionais, testemunhos de evolução quaternária em que têm se sucedido fases paleoambientais e paleoclimáticas distintas, que contribuíram para a constituição da paisagem regional.

Próximo à entrada do PEVV observou-se a constituição do aluvião de tributário da margem esquerda do Rio Quebra-Perna, que apresenta material argilo-arenoso dominante, escurecido pela presença de quantidade variável de matéria orgânica, localmente aparecendo lentes de cascalho com seixos de arenito e concreção limonítica.

Estruturas Geológicas Os contatos entre os diferentes tipos de unidades rochosas de Vila Velha são usualmente paralelos, transicionais, como é o caso da Formação Ponta Grossa sobre a Formação Furnas, ou erosivos e bruscos, como é o caso do Grupo Itararé sobre as formações Ponta Grossa e Furnas.

Entretanto, a região é bastante afetada por estruturas rúpteis de direções WNW-ESE, ENE-WSW e E-W, as quais localmente constituem contato entre diferentes unidades rochosas. Essas estruturas, em sua maioria ligadas ao arqueamento crustal denominado Arco de Ponta Grossa, são fraturas e falhas, que em alguns casos alojam diques de diabásio. As falhas apresentam rejeito vertical significativo, uma vez que colocam lado a lado rochas de níveis estratigráficos distintos.

As estruturas rúpteis controlam a drenagem, encaixando os talvegues de vários dos arroios e rios do parque, destacando-se o Rio Quebra-Perna e afluentes de sua margem esquerda. Têm também grande influência na erosão subterrânea e evolução das formas típicas da região (furnas, lagoas, depressões), como já salientado por Maack (1956), Soares (1989) e Melo et al. (2000). Influenciam ainda a evolução de formas erosivas de superfície, como as fendas no platô arenítico nas proximidades da Gruta da Pedra Suspensa, e a percolação e precipitação de cimento ferruginoso e manganesífero, formando as pseudo-estratificações.

As estruturas sedimentares também exercem influência sobre os processos erosivos, como é o caso do desenvolvimento de túneis anastomosados e cones de dissolução ao longo de descontinuidades subhorizontais no contato entre estratos do Arenito Vila Velha.

GEOMORFOLOGIA DO PEVV O relevo na área do PEVV é dominado por colinas amplas, com morros testemunhos que sustentam platôs areníticos elevados até a altitude de $1068 \mathrm{~m}$. A drenagem principal é representada pelo Rio Guabiroba, um afluente da margem direita do Rio Tibagi. O Rio Guabiroba, cujo leito a jusante encontra-se na cota $780 \mathrm{~m}$, faz o limite sul do PEVV. Vários afluentes da margem direita do Guabiroba aparecem na área do PEVV, destacando-se, de leste para oeste, o Rio Barrozinho (limite leste do parque), o Rio Quebra-Perna (principal rio no interior do parque), o Arroio da Roça e o Arroio Capão Grande (limite oeste do parque).

As rochas e as estruturas geológicas influenciam marcadamente os principais traços do relevo do PEVV, encaixando a drenagem, controlando a distribuição de setores homogêneos (Muratori et al.2002), condicionando feições de relevo particulares, em diversas escalas de tamanho (Melo \& Coimbra 1996; Melo et al. 2002). Estas feições constituem a razão de ser do PEVV, e desde há muito tempo constituem referência para os antigos habitantes e viajantes da região. Entre estas feições, pode-se destacar:

- escarpamentos: penhascos verticais sustentadas pelos arenitos da Formação Furnas e Grupo Itararé;

- morros testemunhos: elevações com topo aplainado, sustentadas por rochas relativamente mais resistentes à erosão, como é o caso do Arenito Vila Velha;

- relevos ruiniformes (ruiniform landscapes segundo Mainguet 1972, apud Wray 1997): a expressão foi cunhada para a região de Roraima, no sul da Venezuela, com paisagens desfeitas, com muitos penhascos de até $1 \mathrm{~km}$ em ortoquartzitos proterozóicos; no PEVV os relevos ruiniformes aparecem no Arenito Furnas e em arenitos do Grupo Itararé (Fig. 5);

- torres e pináculos: formados por erosão mecânica e/ou dissolução (intemperismo químico de feldspato e cimento ferruginoso ou caulínico seguido de remoção mecânica dos grãos na zona vadosa); a "taça" é uma torre típica (localização na Fig. 5);

- cavernas, dolinas, poços de dissolução, sumidouros, vales secos: feições típicas de relevos cársticos, onde a dissolução dos minerais das rochas é importante na elaboração das formas; embora sejam feições típicas de áreas de rochas carbonáticas, ocorrem também nos arenitos da área do PEVV, principalmente a Formação Furnas, onde o cimento caulínico pode sofrer dissolução;

- fendas, corredores e labirintos: alargamento de juntas que canalizam a água, por dissolução e erosão mecânica; a Gruta da Pedra Suspensa no PEVV é na verdade um sistema de fendas;

- furnas: um tipo de "poços de desabamento" (sinkholes), formados pelo desabamento do teto de grandes cavidades subterrâneas; no PEVV ocorrem várias furnas, sendo as mais conhecidas as chamadas furna $\mathrm{n}^{\circ} 1$ (onde existe elevador e plataforma flutuante), furna $n^{\circ} 2$ (onde existe mirante), furna $n^{\circ} 3$ (seca, atualmente interditada para visitação), furna $n^{\circ} 4$, Lagoa Dourada (considerada uma furna assoreada) e Lagoa Tarumã (Fig. 5);

- depressões úmidas e secas (dales) e lagoas: formadas pela lixiviação/erosão mecânica subterrânea de componentes dos arenitos;

- cachoeiras e corredeiras: quedas d'água e áreas de estrangulamento da drenagem, que sofre influência das rochas pouco sujeitas ao intemperismo (arenitos) e estruturas (falhas, diques, fraturas);

- lapas: abrigos formados por tetos naturais que protegem reentrâncias rochosas formadas por diversos processos (erosão mecânica, dissolução, etc.); são muito comumente sítios arqueológicos;

- entalhes de base de paredes rochosas (solution notches, entalhes basais, covas de pé-de-escarpa): formam-se onde solos bordejam superfícies rochosas verticais, aparentemente em consequiência da alteração associada à percolação de águas de infiltração e do solo; a base dos rochedos torna-se côncava; 
- caneluras ou canaletas (runnels, karren, lapiés, gutter, rills): pequenas feições e canais de drenagem formados por dissolução e/ou erosão mecânica diretamente pelas águas meteóricas;

- bacias de dissolução (solution basins, grammas, weathering pans, pits, opferkessel, rock tanks): pequenas depressões com fundo aplainado em rochas silicosas (e outras), atribuídas a dissolução dominante, pela ação de águas pluviais estagnadas; podem coalescer ou interligar-se por canaletas; ocorrem nos arenitos da Formação Furnas e Grupo Itararé;

- alvéolos (tafoni): escavações superficiais promovidas pelas águas pluviais, por ação de erosão mecânica e dissolução;

- túneis anastomosados e cones de erosão: feições originadas por erosão mecânica e dissolução, controladas por juntas horizontais;

- juntas poligonais: abertura, por efeito de dissolução/erosão mecânica, de juntas poligonais formadas aparentemente pela insolação;

- perfurações produzidas por cupins: perfurações em rochas, sobretudo arenitos, atribuídas a cupins (tubos termíticos); a origem é interpretada pelos padrões construtivos (geometria, orientação, diâmetro).

Um notável equívoco consagrado nos livros de ensino fundamental e médio e mesmo em livros geológicos relaciona-se com a gênese de algumas formas típicas do PEVV, como é o caso da torre representada pela "taça", escultura símbolo do parque. Embora desde trabalhos pioneiros (Taunay 1890) a ação das águas meteóricas seja apontada como a responsável pelas formas de Vila Velha, freqüentemente a "taça" é referida como forma resultante da ação do vento. Na verdade sua origem é devida a uma combinação de fatores, incluindo variação faciológica do arenito, presença de estruturas rúpteis e ação de águas pluviais (Melo 2002).

A GEOLOGIA NO PLANO DE MANEJO DO PEVV NoS planos de manejo de unidades de conservação, os principais objetivos são o diagnóstico dos potenciais e fragilidades da área, e o zoneamento que apóie o disciplinamento das formas de utilização (IBAMA 2002). No caso do PEVV, cujos principais atrativos são geológicos e geomorfológicos, a avaliação geológica assumiu relevância relativamente a outros aspectos, ligados a fatores bióticos. Os principais subsídios da Geologia para o plano de manejo são descritos a seguir.

Áreas ou temas de interesse específico para visitação Trata-se da identificação de ocorrências ou exposições singulares de aspectos geológicos ou geomorfológicos, que podem constituir-se em atrativos para visitações de leigos ou especialistas, com finalidade didática. Além de constituírem assuntos de interesse no meio acadêmico e estudantil, é desejável que as exposições na unidade de conservação sejam excepcionalmente favoráveis. No PEVV pode-se destacar, entre outros, vários temas ou áreas específicas:

- exposições de atributos das rochas sedimentares (Formação Furnas e Arenito Vila Velha) e interpretação dos processos formadores;

- fósseis devonianos da Formação Ponta Grossa (Fig. 5);

- pseudo-estratificações no Arenito Vila Velha (Fig. 5); Velha.

- processos e formas de erosão dos arenitos Furnas e Vila

Proteção de áreas especiais Algumas situações que expõem de forma privilegiada aspectos geológicos e geomorfológicos de interesse podem vir a ser prejudicadas pelos equipamentos e instalações na unidade de conservação. Então é necessário que a in- tervenção do especialista advirta para os prejuízos e riscos que podem resultar. No PEVV uma situação deste tipo é a antiga trilha sobre pseudo-estratificações no Arenito Vila Velha, originadas por franjas diferenciadas de óxidos de ferro e manganês a partir de fraturas (Fig. 5). O local de exposição vem sendo erodido e degradado pelo pisoteio e inscrições dos visitantes, sendo necessária orientação sobre o significado das estruturas e importância de sua proteção, bem como realocação das trilhas e uso de equipamentos alternativos, como passarelas suspensas.

Recuperação de áreas degradadas e prevenção Por tratar-se de área visitada há muito tempo, e administrada por instituições com objetivos e procedimentos muito distintos, o PEVV apresenta alguns problemas sui generis. É o caso de duas áreas degradadas pela remoção do horizonte superficial do solo, para uso em aterros, que mostram solo exposto sob ação de processos erosivos (Fig. 5). Uma outra situação de degradação é observada em alguns dos caminhos internos utilizados para acesso e vigilância do parque, que vêm apresentando processos erosivos, em consequiência da escolha de traçados inadequados, em pendentes das encostas, ou sobre solos muito frágeis (Fig. 5). Nestes dois casos, além da orientação técnica na recuperação das áreas degradadas é possível extrair critérios para evitar novas degradações.

Utilização de materiais de construção A história recente do PEVV também oferece um exemplo contundente de uso inadequado de materiais de construção, às vezes necessários para a estabilização de trilhas e outros equipamentos. Diante da necessidade de melhorar o piso de uma das trilhas (trilha sul do platô arenítico principal, Fig. 5), muito úmida, escorregadia e sujeita à erosão, foi utilizado um cascalho proveniente do intemperismo de folhelhos da Formação Ponta Grossa, onde além dos atributos da rocha, ainda era possível encontrar moldes de fósseis devonianos. Ou seja, os trabalhos de melhoria da trilha criaram uma situação inusitada de inversão estratigráfica, colocando folhelhos com fósseis devonianos sobre o arenito carbonífero.

Outro exemplo de utilização indevida de materiais no PEVV foi o lançamento de latossolos de folhelhos da Formação Ponta Grossa em trilhas em erosão pelo uso intensivo. Embora os latossolos constituam materiais sujeitos a compactação, mais estáveis, são totalmente estranhos à paisagem natural do parque.

Pode-se citar também uma discussão que cercou, há algum tempo, a necessidade de escolha de material rochoso resistente, para reforço de algumas trilhas e muros do parque. Entre as opções, falou-se em abrir uma pedreira em arenitos da região, ou utilizar o Arenito Botucatu, do qual existem pedreiras no norte do Estado do Paraná. Esta última opção apresenta algumas conveniências, pois o Arenito Botucatu é resistente, já é explorado e, embora tenha idade, origem e alguns atributos muito diferentes, tem um aspecto geral, avermelhado, semelhante ao Arenito Vila Velha. Já a opção de abertura de pedreira parece inconveniente, pois trata-se de rochas reconhecidamente frágeis, e a nova lavra implicaria em fonte de impactos numa região destinada à preservação. Alternativa preferível seria a utilização do Arenito Lapa, geneticamente associado ao arenito Vila Velha, e do qual já existem lavras nas proximidades da cidade da Lapa, situada cerca de $80 \mathrm{~km}$ a sudoeste de Ponta Grossa.

Indicação de possíveis situações de risco Em quatro locais do PEVV foram observados blocos rochosos instáveis, descalçados em decorrência de processos erosivos naturais. O mais notório destes blocos é a chamada "pedra suspensa", na "gruta" homôni- 
ma (Fig. 5), na realidade um sistema de fendas, muito visitado. É necessário que estes blocos sejam alvo de ensaios de estabilidade e, se for o caso, procedimentos de estabilização ou restrição de acesso, de modo a garantir a segurança dos visitantes.

Outra situação de risco é associada aos desníveis em feições geomorfológicas como as furnas, fendas e escarpamentos. Neste caso, as proximidades da furna $\mathrm{n}^{\circ} 4$, do sistema de fendas próximo à Gruta da Pedra Suspensa e das escarpas do platô principal de Vila Velha e da Fortaleza são os principais locais de risco (Fig. 5).

Indicação de equipamentos específicos Vários equipamentos específicos podem ser indicados para orientar, divulgar e/ou proteger as exposições de interesse geológico. É o caso das passarelas para preservação das pseudo-estratificações, de coberturas para proteção de área de exposição de fósseis devonianos e painéis ilustrativos e explicativos das principais feições expostas.

Indicação deáreas para desenvolvimento denovos atrativos Várias novas possibilidades de atrativos foram identificadas dentro do perímetro do PEVV (Fig. 5): ocorrência de fósseis devonianos na Formação Ponta Grossa, excepcionais exposições dos arenitos da Formação Furnas, labirinto de fendas do platô arenítico nas proximidades da Gruta da Pedra Suspensa (ambiente cavernícola singular dentro dos limites do parque). Estas áreas poderão ser desenvolvidas, pela pesquisa de seus múltiplos atributos e adequação de acessos e orientação, para constituir-se em novos atrativos para os visitantes do parque.

Indicação de temas para novas pesquisas Os levantamentos realizados indicaram alguns temas que poderão vir a ser objeto de novas pesquisas. Entre eles, pode-se destacar:

- controle estrutural e litológico das feições erosivas subterrâneas e suas correspondentes superficiais (furnas, lagoas, depressões, etc.);

- possível ocorrência de sítios arqueológicos nos muitos abrigos naturais na Formação Furnas na margem esquerda do Rio Quebra-Perna;

- sistematização das evidências dos processos deposicionais dos arenitos Furnas e Vila Velha;

- sistematização dos processos e formas erosivas superficiais nos arenitos;

- investigação de registros paleoclimáticos e paleoambientais no preenchimento sedimentar de lagoas e depressões do parque.

Indicação de eventuais áreas de ampliação da UC Como usualmente os limites das unidades de conservação não são naturais, mas respondem a fatores fundiários ou outros, é comum que os levantamentos de maior detalhe revelem feições de interesse que se prolonguem para além da área protegida. No caso do PEVV, seria muito oportuna a ampliação da área protegida para as nascentes do Rio Quebra-Perna, para norte dos limites atuais do parque. Lá ocorrem sítios singulares (Sumidouro, Buraco do Padre, Furnas Gêmeas, Furna Grande, escarpamentos, lajeados, sítios arqueológicos), e significativos remanescentes preservados de mata e campo nativos.

Indicação de atividades de interpretação ambiental Uma tendência que enfeixa as preocupações das atividades práticas tão necessárias em Geologia e os princípios da Educação Ambiental é a interpretação ambiental, que visa motivar os participantes na descoberta dos mecanismos ambientais através da observação e compreensão de evidências coletadas, por exemplo, ao longo de trilhas na unidade de conservação (Wood \& Wood 1990).

Alguns aspectos ligados aos fatores abióticos poderão ser abordados nas atividades de interpretação ambiental, tais como a origem das formas de Vila Velha, o desenvolvimento dos processos erosivos, possíveis relações entre rochas, solos, dinâmica da água e vegetação.

Produção de material de informação, divulgação e treinamento OPEVV também oferece bons exemplos de produção de material de informação, divulgação e treinamento contendo informações inadequadas ou equivocadas. O principal é a já mencionada falácia de que as formas de relevo resultam de erosão eólica. Existem outros equívocos consagrados, tais como a atribuição do nome da Lagoa Dourada, na verdade uma alusão ao reflexo do sol visível em certas horas do dia, à abundante presença de mica brilhante no seu sedimento de fundo e confusões envolvendo a idade de formação das rochas e das formas elaboradas sobre elas.

Treinamento de recursos humanos Todas estas considerações sobre aspectos geológicos relacionados com o manejo do PEVV leva a uma conclusão natural: é necessário que o uso do parque pelos visitantes, sejam estes especialistas ou turistas, seja orientado por pessoal com treinamento adequado, que só pode ser oferecido por profissionais qualificados. Os aspectos geológicos do PEVV devem ser apresentados por quem tenha suficiente conhecimento sobre eles, assim como os aspectos botânicos, faunísticos, climáticos, etc. deverão ser apresentados pelos respectivos profissionais de área.

CONCLUSÕES A história recente do PEVV oferece muitos exemplos de aspectos geológicos e geomorfológicos conduzidos equivocadamente: degradação de feições de interesse (pseudoestratificações), uso de materiais alóctones indevidos (folhelho devoniano, latossolos), áreas degradadas por caixas de empréstimo, divulgação de informações errôneas (erosão eólica, mica na Lagoa Dourada, idade das rochas e das formas).

Mas é na ampliação das atividades realizáveis nas unidades de conservação que está a maior possibilidade de contribuição da Geologia: proposição de novas pesquisas, desenvolvimento de atrativos para público leigo e especializado, proposição de atividades de interpretação da natureza, treinamento de pessoal, produção de material de divulgação com informação técnica e científica adequada.

Agradecimentos Aos revisores da RBG pelas sugestões ao manuscrito.

\section{Referências}

Assine M.L. 1996. Aspectos da estratigrafia das sequiências précarboníferas da Bacia do Paraná no Brasil. São Paulo, Tese de Doutorado, IG-USP, 207p.

Assine M.L., Soares P.C., Milani É.J. 1994. Seqüências tectono- sedimentares mesopaleozóicas da Bacia do Paraná, sul do Brasil. São Paulo, Rev. Bras. Geoc., 24:77-89.

Assine M.L., Perinotto J.A.J., Fúlfaro V.J., Petri S. 1998. Progradação deltaica Tibagi no Devoniano Médio da Bacia do Paraná. São Paulo, 
Rev. Bras. Geoc., 28:125-134.

Bergamaschi S. 1999. Análise Estratigráfica do Siluro-Devoniano (Formações Furnas e Ponta Grossa) da Sub-Bacia de Apucarana, Bacia do Paraná, Brasil. Tese de Doutorado, IG-USP, 167p.

Bigarella J.J., Salamuni R., Marques Filho P.L. 1966. Estruturas e texturas da Formação Furnas e sua significação paleogeográfica. Bol. UFPR, 18:1-114. (Geologia).

Borgui L. 1996. A Formação Furnas revisada no bordo leste da Bacia do Paraná. In: PMPG-UEPG-UFPR, Simp. Sul-Americano do SiluroDevoniano, Ponta Grossa, Anais, p.13-28.

Boucot A.J. \& Gill E.D. 1956. Australocoelia, a new Lower Devonian brachiopod from South Africa, South America and Australia. J. Paleont., 30:1173-1178.

Campanha G.A. \& Sadowski G.R. 1998. Tectonics of the southern portion of the Ribeira Belt (Apiaí Domain). J. African Earth Sci, 27:220-221.

Canuto J.R., Rocha-Campos A.C., Sato P.E.S. 1997. The Late Paleozoic Lapa Sandstone (Itarare Subgroup): a possible tunnel-valley fill?. Anais Acad. Bras. Ciên., 69:275-276.

Chmyz I. 1976. Nota prévia sobre o sítio PR PG 1: abrigo-sob-rocha Cambiju. Curitiba, Estudos Brasileiros, 2:231-246.

Daemon R.F., Quadros L.P., Silva A. 1967. Devonian palynology and biostraigraphy of the Paraná Basin. In: Bigarella, J.J. (ed.). Problems in brazilian Devonian geology. Bol. Paran. Geoci., 21/22: 99-132.

França A.B. \& Potter P.E. 1988. Estratigrafia, ambiente deposicional e análise de reservatório do Grupo Itararé (Permo-Carbonífero), Bacia do Paraná. Bol. Geoci. PETROBRÁS, 2:147-191.

França A.B., Winter W.R., Assine M.L. 1996. Arenitos Lapa-Vila Velha: um modelo de trato de sistemas subaquosos canal-lobos sob influência glacial, Grupo Itararé (C-P), Bacia do Paraná. Rev. Bras. Geoc., 26:43-56.

Herz N. 1977. Timing of spreading in South Atlantic: information from brazilian alkalic rocks. Geol. Soc. Am. Bull., 88:101-102.

IBAMA. 2002. Roteiro Metodológico e Planejamento-Parques Nacionais, Reserva Biológica e Estação Ecológica. Brasília, 136pp.

Isaacson P.E. 1996. Devonian biogeography and paleogeography of western Gondwana: malvinokafric endemism, faunal migration, and organic microfossil provincialism. In: PMPG-UEPG-UFPR, Simp. Sul-Amer. Siluro-Devoniano, Ponta Grossa, Anais, p.193-217.

Lange F. W. \& Petri S. 1967. The Devonian of Paraná Basin. Bol. Paranaense de Geoc., 21/22:5-55.

Maack R. 1946. Geologia e geografia da região de Vila Velha e considerações sobre a glaciação carbonífera do Brasil. Arq. Museu Paran., 5:305p.

Maack R. 1947. Breves notícias sobre a geologia dos estados do Paraná e Santa Catarina. Curitiba, IBPT, Arq. Biol. Tecnologia, II: 63-154.

Maack R. 1956. Fenômenos carstiformes de natureza climática e estrutural nas regiões de arenitos do Estado do Paraná. Curitiba, IBPT, Arq. Biol. Tecnol., XI:151-162.

Melo M.S. 1999. Análise sedimentológica dos depósitos da Lagoa Dourada, Vila Velha, Ponta Grossa, PR. Relatório de pesquisa, UEPG-DEGEO, Ponta Grossa, 74p.

Melo M.S. 2002. Vila Velha, PR - resultado do trabalho do vento? Revista Publicatio UEPG-Ciências Exatas e da Terra, Ciências Agrárias e Engenharia, 8:7-26.
Melo M.S. \& Coimbra A.M. 1996. Ruiniform relief in sandstones: the example of Vila Velha, Carboniferous of the Paraná Basin, Southern Brazil. Acta Geologica Hispanica, 31:25-40.

Melo M.S., Coimbra A.M., Sayeg I.J., Giannini P.C.F., Atêncio D. 1999. Fringed cryptomelane / hollandite in the Vila Velha Sandstone telogenesis. Acta Microscopica, 8(A):35-36.

Melo M.S., Giannini P.C.F., Pessenda L.C.R. 2000. Gênese e evolução da Lagoa Dourada, Ponta Grossa, PR. Rev. do Inst. Geol., 21:17-31.

Melo M.S., Bosetti E.P., Godoy L.C., Pilatti F. 2002. Vila Velha, PR: impressionante relevo ruiniforme. In: C. Schobbenhaus, D.A . Campos, E.T. Queiroz, M. Winge, M. Berbert-Born (eds.) Sítios Geológicos e Paleontológicos do Brasil. Brasília, DNPM-CPRMSIGEP, pp.: 269-277.

Milani É.J., França A.B., Schneider R.L. 1994. Bacia do Paraná. Bol. Geoc. PETROBRÁS, 8:69-82.

Milani É.J., Faccini U.F., Scherer C.M., Araújo L.M., Cupertino J.A. 1998. Sequences and stratigraphic hierarchy of the Paraná Basin (Ordovician to Cretaceous), Southern Brazil. Bol. IG-USP, 29:125-173.

Muratori A.M., Melo M.S., Godoy L.C., Kossovski E.L., Meneguzzo P.M., Silva D.J. 2002. Geomorfologia do Parque Estadual de Vila Velha. In: 4 Jornada Científica de Geografia da UEPG, Ponta Grossa, 2002. Bol. Resumos, p.101-103.

Northfleet A.A., Medeiros R.A., Mühlmann H. 1969. Reavaliação dos dados geológicos da Bacia do Paraná. Bol. Geoci. PETROBRÁS, 12:291-346.

Rocha C.H., Michalizen V., Pontes Filho A. (Coords.) Plano de integração Parque Estadual de Vila Velha - Rio São Jorge. Ponta Grossa, Itupahva - PMPG. s.d.

Santana A.C. \& Melo M.S. 2001. Sumidouro do Rio Quebra-Perna, Ponta Grossa, PR: um complexo de informações geográficas. In: UEPG, 3 Jornada Científica de Geografia, Bol. Resumos, p.70-72.

Schneider R.L., Mühlmann H., Tommasi E., Medeiros R.A., Daemon R.F., Nogueira A.A. 1974. Revisão estratigráfica da Bacia do Paraná. In: SBG, Congr. Bras. Geol. 28, Porto Alegre, Anais, v.1, p.41-65.

Soares O. 1989. Furnas dos Campos Gerais, Paraná. Curitiba, Scientia et Labor, 82p. (Editora da UFPR, Série Didática).

Universidade Estadual de Ponta Grossa. 2002. Geologia e Geomorfologia do Parque Estadual de Vila Velha. Relatório Científico, Ponta Grossa, UEPG-DEGEO, 35p.

Wood D.S. \& Wood D.W. 1990. Como planificar un programa de educacion ambiental. Washington, Center for International Development and Environment of the World Resources Institute and the United States Fish and Wild Life Service, 46p.

Wray R.A.L. 1997. A global review of solutional weathering forms on quartz sandstones. Earth Science Reviews, 42:137-160.

Zalán P.V., Wolff S., Conceição J.C.J., Marques A., Astolfi M.A.M., Vieira I.S., Appi V.T., Zanotto O.A. 1991. Bacia do Paraná. In Gabaglia G.R. \& Milani E.J. (Eds.) Origem e evolução de bacias sedimentares. Rio de Janeiro, PETROBRÁS, pp.: 135-168.

Manuscrito A-1445

Recebido em 12 de junho de 2003

Revisão dos autores em 28 de julho de 2004 Revisão aceita em 30 de julho de 2004 